\title{
Detection of adverse drug reaction (ADR)-related hospital admissions: A pilot study using administrative database for ADR monitoring in Thailand
}

C. Siltharm ${ }^{l}$, O. Pattanaprateep ${ }^{2}$, P. Pongcharoensuk ${ }^{l}$, N. Jeanpeerapong ${ }^{3}$, M. Thavorncharoensap ${ }^{1, *}$ ${ }^{I}$ Division of Social and Administrative Pharmacy, Department of Pharmacy, Faculty of Pharmacy, Mahidol University, Thailand

${ }^{2}$ Section for Clinical Epidemiology and Biostatistics, Faculty of Medicine Ramathibodi Hospital, Mahidol University, Thailand

${ }^{3}$ Buddhachinaraj Phitsanulok Hospital, Phitsanulok, Thailand

\begin{abstract}
This study aims to examine incidence, characteristics, and trend of ADR-related admissions at one tertiary care hospital in Thailand during a five-year period (2007-2011), using administrative database and spontaneous report. Data of all hospitalized patients during the year 2007 to 2011 were retrospectively obtained from routine administrative database. The 10th International Classification of Diseases (ICD-10) was used to identify patients with ADR. The number of admissions with the following diagnosis codes; "adverse drug reaction", "drug-induced", "due to drug", "due to medicament", "drug allergy" or "external causes code" (Y40-Y59) were obtained and analyzed. During the year 2007 to 2011, incidence of ADR-related hospital admissions detected through hospital database and spontaneous report was estimated at $2.74 \%$, and $0.71 \%$, respectively. Using the administrative database, incidence of ADR-related hospital admissions was increasing from $1.29 \%$ (2007) to $3.75 \%$ (2010) and then slightly decreasing to $3.47 \%$ in 2011 . The most commonly involved drugs were hormones and their synthetic substitutes and antagonists (Y42; 23.8\%), systemic antibiotics (Y40; 13.2\%), agents primarily affecting blood constituents (Y44; 12.6\%), and primarily systemic agent (Y43; 9.3\%), respectively. Drug-induced neutropenia (46.35\%), drug-induced hypoglycemia without coma (27.01\%), and generalized skin eruption (11.06\%) were the three most common ADRs identified from database. ADR-related hospital admission was an increasing important public health problem. Effort should be made to implement effective measure to reduce ADRs and to make greater use of administrative database to continuously monitor patient safety in national perspective.
\end{abstract}

Keyword: Adverse drug reaction, spontaneous report, database, pharmacovigilance, admission, monitoring

\section{INTRODUCTION}

According to the World Health Organization (WHO), ADR is "a response to a drug that is noxious and unintended and occurs at doses normally used in man for the prophylaxis, diagnosis or therapy of disease, or for modification of physiological function". ADR is a common public health problem leading to considerable morbidity, mortality, and extra costs ${ }^{2-4}$. Detection and reporting ADR is crucial for improving and monitoring drug safety ${ }^{5}$. According to a review of the 25 prospective studies, prevalence of ADRs among hospitalization patients was estimated at
$5.3 \%{ }^{6}$. Nevertheless, more recent reviews found that prevalence of ADR related hospitalization was approximately $17 \%{ }^{7}$ while ranging between $0.1 \%$ to $54 \%$. It should be noted that findings from the reviews ${ }^{6-8}$ indicated high variation in prevalence of ADR across studies. This variation could possibly be explained by methodology used for ADR, methodology quality, settings, and population $^{6-8}$.

With respect to ADR identification methods, intensive methods for ADR detection such as medical chart review or intensive monitoring consistently found higher prevalence 
rates for ADRs than analysis of database and spontaneous reporting ${ }^{6-9}$. Nevertheless, medical chart review and intensive monitoring require high resource and technical intensive. In contrast, spontaneous reporting is a major method used globally to identify and to monitor ADRs. Although it is the easiest and cheapest method underreporting ${ }^{10}$ and poor quality reports ${ }^{11}$ are major concerns of this method.

Similar to spontaneous report, the use of administrative database required few resource and financial burden but resulted in higher rate of ADR detection. As the result, administrative database has substantial potential to be continuously used to monitor ADRs for national perspective as supplement to established methods such as spontaneous report. In fact, the use of hospital administrative data is proven to be a reliable and valid method for monitoring patient's safety in several developed countries ${ }^{12-19}$. To our knowledge, no study has been conducted to determine the prevalence of ADR among hospitalized patients in less developed country using administrative database before.

As compared to other countries, incidence of ADRs among hospitalized patients in Thailand was also high ranging between $1.7 \%$ to $22.6 \%$ depending on methods, study settings and also study population ${ }^{20}$. It should be noted that all previous studies conducted in Thailand to examine prevalence of ADR among hospitalized patients ${ }^{21-25}$ were short-term studies conducted using intensive ADR monitoring method in a few wards. Similar to many countries, spontaneous reporting system is a major method for ADR identification in Thailand. The aims of our study are to examine incidence and characteristics of ADR- related hospital admission using routine administrative database at one tertiary care hospital in Thailand, and to compare the incidence of ADR-related hospital admission identified using routine administrative database and spontaneous report.

\section{MATERIALS AND METHODS}

\subsection{Study design}

A retrospective study was conducted using hospital administrative database of one tertiary hospital in the northern region of Thailand during 2007 to 2011. The database is maintained by the hospital and is used for reimbursement purpose. The database contains information on patient identification, age, gender, admission date, discharge date, diagnosis relate group (DRG), and ICD-10 ${ }^{\text {th }}$ of all patients admitted to the hospital. This study was approved by the Mahidol University Institutional Review Board (MU-IRB), Thailand.

\subsection{ADR identification}

From 2007 to 2011, ADR-related hospital admissions were identified using the ICD-10 ${ }^{\text {th }}$ code which contained the following keywords: "adverse drug reaction, "drug-induced", "due to drug", "due to medicament"), as shown in Table 1. ICD-10 $0^{\text {th }}$ code Y40-Y59, which are the additional codes used to indicate an "external cause" relevant to drugs were also used to identified ADR related admission (Table 2). This excludes accidental or intentional poisoning due to drugs. Duplicated records were removed by matching date of birth, gender, date of admission, and date of discharge. Data on spontaneous ADR reporting during the study period were also obtained from the hospital to calculate the incidence of ADR- related hospital admissions.

Incidence of ADR-related hospital admissions and characteristics of ADR-related hospital admissions were analyzed using descriptive statistics (frequency, percentage, mean \pm standard deviation). Data were analyzed by Microsoft Access version 2013 and Microsoft Excel version 2013. 
Table 1. ICD-10 for external cause mortality/morbidity

\begin{tabular}{cl}
\hline ICD-10 & \multicolumn{1}{c}{ External cause mortality/ morbidity by: } \\
\hline Y40 & $\begin{array}{l}\text { Systematic antibiotics: Penicillins, cefalosporins and other beta-lactam antibiotics, } \\
\text { macrolides, tetracyclines, aminoglycosides, rifamycin, antifungals, others }\end{array}$ \\
Y41 & $\begin{array}{l}\text { Other systematic anti-infectives and antiparasitics: Sulphonamides, other anti- } \\
\text { mycobacterial, anti-malarials, anti-protozoal, anti-helminthics, anti-virals }\end{array}$ \\
Y42 & $\begin{array}{l}\text { Hormones and substitutes: Glucocorticoids, thyroid hormones, anti-thyroids, } \\
\text { insulin, oral hypoglyceamics, oral contraceptives, oestrogen and progestogen, anti- } \\
\text { gonadotrophins, anti-oestrogens, anti- progestogen, androgens }\end{array}$
\end{tabular}

Y43 Systemic agents: anti-allergic and anti-emetic drugs, anti-neoplastic and immunosuppressive drugs, acidifying/ alkalizing agents

Y44 Agents affect blood constituents: Iron preparations, anti-megaloblastic-anemia preparations, anticoagulants antagonists, antithrombotic drugs, thrombolytic drugs, blood products, plasma substitutes

Y45 Analgesics, anti-pyretics and anti-inflammatory drugs: Opioids and related analgesics, salicylates, propionic acid derivatives, nonsteroidal anti-inflammatory drugs, antirheumatics, 4-aminophenol derivatives

Y46 Anti-epileptics and anti-parkinsonism drugs: Succinimides, oxazolidinediones, hydatoin derivatives, deoxybarbiturates, iminostibenes, valproic acid, anti- parkinsonism drugs, anti-spasticity drugs

Y47 Sedatives, hypnotics and anti-anxiety drugs: Barbiturates, benzodiazepines, cloral derivatives, paraldehyde, bromine compounds, sedative, hypnotics and anti-anxiety drugs, unspecified

Y48 Anaesthetics and therapeutic gases: Inhaled/ parenteral anaesthetics, local anaesthetics, therapeutic gases

Y49 Psychotropic drugs: Tricyclic and tetracyclic antidepressants, monoamine-oxidaseinhibitor, phenothiazine antipsychotics and neuroleptics, butyrophenone and thioxanthene neuroleptics, other antidepressants, antipsychotics and neuroleptics

Y50 Central nervous system stimulants: Analeptics, opioid receptor antagonists, , methylxanthines, other central nervous system stimulants

Y51 Drugs primarily affecting the autonomic nervous system: Anticholinesterase agents, cholinergics, ganglionic blocking drugs, anti cholinergics, antimuscarinics, spasmolytics, alpha-adrenoreceptor agonists/ antagonists, beta-adrenoreceptor agonists/ antagonists, centrally acting and adrenergic-nervous-blocking agents

Y52 Agents affecting the cardiovascular system: Cardiac-stimulant glycosides, calcium-channel blockers, other anti-dysrhythmic drugs, other coronary vasodilators, angiotensin-converting-enzyme inhibitors, other anti-hypertensives, anti-hyperlipidaemic and anti-arteriosclerotic drugs, peripheral vasodilators, anti-varicose drugs 


\begin{tabular}{|c|c|}
\hline ICD-10 & External cause mortality/ morbidity by: \\
\hline Y53 & $\begin{array}{l}\text { Agents affecting the gastrointestinal system: Antacids, anti-gastric-secretion } \\
\text { drugs, laxatives, anti-diarrhoeal, emetics }\end{array}$ \\
\hline Y54 & $\begin{array}{l}\text { Agents affecting water-balance and mineral and uric metabolism: Mineralocor- } \\
\text { ticoids, mineralocorticoids antagonists, carbonic-anhydrase inhibitors, benzothaidi- } \\
\text { azine derivatives, other diuretics, electrolytic, caloric and water-balance agents, } \\
\text { agents affecting calcification, agents affecting uric acid metabolism }\end{array}$ \\
\hline Y55 & $\begin{array}{l}\text { Agents acting on smooth and skeletal muscles and the respiratory system: Oxy- } \\
\text { tocic drugs, skeletal muscles relaxants, anti-tussives, expectorants, anti-common- } \\
\text { cold drugs, anti-asthmatics }\end{array}$ \\
\hline Y56 & $\begin{array}{l}\text { Topical agents primarily affecting skin and mucous membrane: Local } \\
\text { anti-fungal, anti-infective, anty-inframmatory drugs, anti-pruritics, local } \\
\text { detergents, emollients, keratolytics, ophthalamological drugs,otrhinolaryngological } \\
\text { drugs, dental drugs }\end{array}$ \\
\hline Y57 & $\begin{array}{l}\text { Other and unspecified drugs: Appetite depressants, lipotropic drugs, antidotes and } \\
\text { chelating agents, alcohol deterrents, X-ray contrast media, vitamin }\end{array}$ \\
\hline Y58 & Bacterial vaccines \\
\hline Y59 & Other vaccines: Viral/ rickettsial/ protozoal vaccines, immunoglobulin \\
\hline
\end{tabular}

Table 2. ICD-10 codes (primary diagnosis codes) for "adverse drug reaction", "drug-induced", "due to drug", "due to medicament" or "drug allergy" causing adverse effects in therapeutic use

\begin{tabular}{ccl}
\hline $\begin{array}{l}\text { ICD-10 ICD-10 } \\
\text { chapter }\end{array}$ & \multicolumn{1}{c}{ codes } & \multicolumn{1}{c}{ Primary cause mortality/ morbidity by: } \\
\hline D & D52.1 & Drug-induced folate deficiency anaemia \\
& D59.0 & Drug-induced autoimmune haemolytic anaemia \\
D59.2 & Drug-induced nonautoimmune haemolytic anaemia \\
D61.1 & Drug-induced aplastic anaemia \\
D64.2 & Secondary sideroblastic anaemia due to drugs and toxins \\
D70 & Agranulocytosis, Agranulocytic angina, Infantile genetic agranulocytosis \\
& Kostmann's disease, Neutropenia: drug-induced \\
E06.4 & Drug-induced thyroiditis \\
E15 & Nondiabetic hypoglycaemic coma \\
& Drug-induced insulin coma in nondiabetic \\
E16.0 & Drug-induced hypoglycaemia without coma \\
E23.1 & Drug-induced hypopituitarism \\
E24.2 & Drug-induced Cushing's syndrome \\
E03.2 & Hypothyroidism due to medicaments and other exogenous substances \\
E27.3 & Drug-induced adrenocortical insufficiency \\
E66.1 & Drug-induced obesity \\
\hline
\end{tabular}




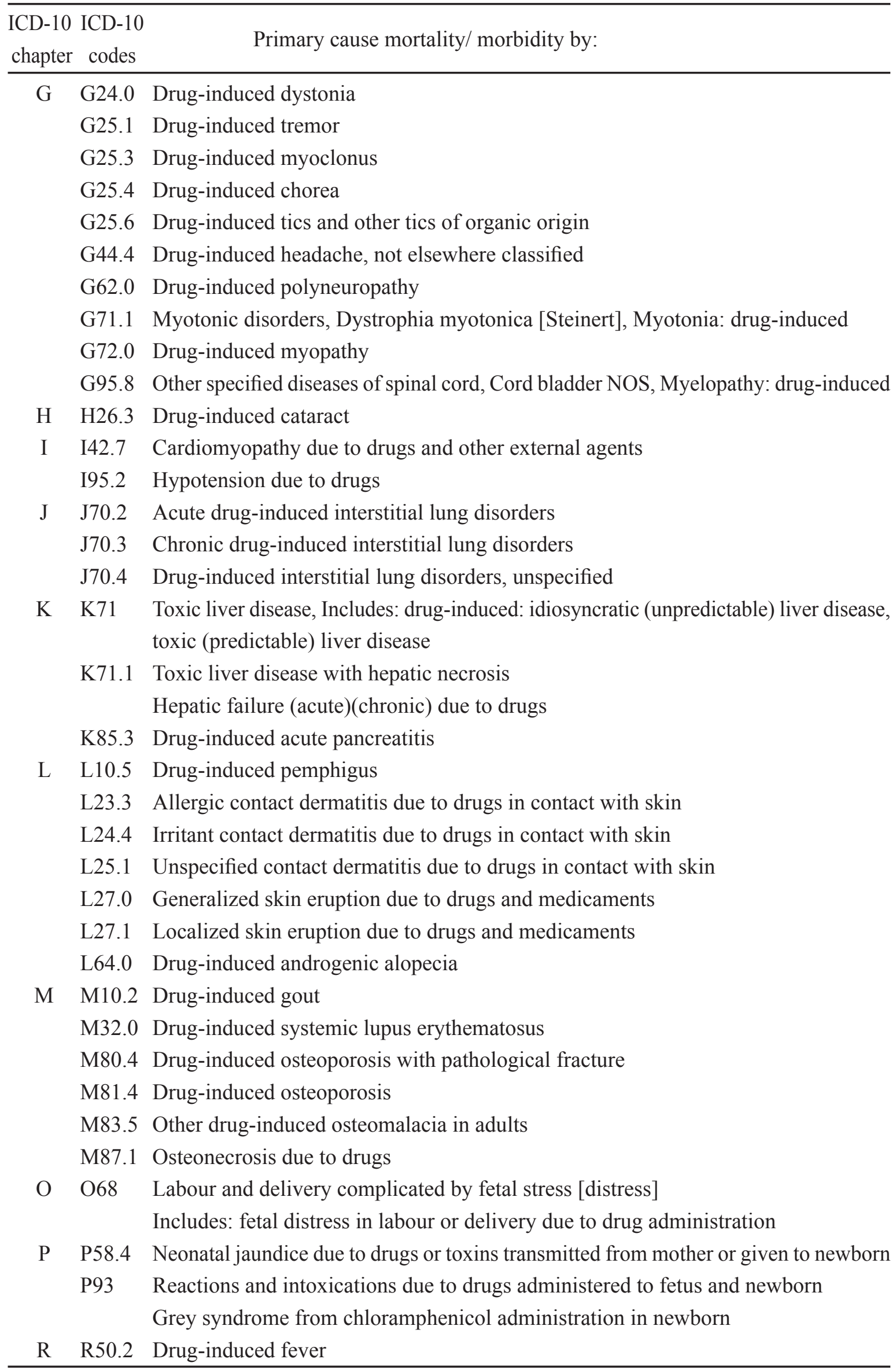




\section{RESULTS}

\subsection{Incidence and 5-year trend of ADR- related hospital admissions}

Table 3 summarizes the annual number of total admissions, incidence and the number of ADR-related admissions identified from administrative and spontaneous report, as well as incidence and the total number of deaths among patients with ADR-related admissions. During the 5-year study period, there were 283,070 admissions and 7,756 admissions with diagnostic code indicative of ADRs (2.74\%). Of these, 3,780 (1.34\%) were "drug induced" codes and 3,976 (1.4\%) were "external cause". As shown in Table 3, during the 5-year study period, incidence of ADRs was increasing from
$1.29 \%$ in 2007 to $3.75 \%$ in 2010 and then slightly decreasing to $3.47 \%$ in 2011 . Between 2007 and 2011, the total number of admissions increased by $17.08 \%$ while the total number of ADR-related admission identified from administrative database increased by $215.57 \%$, resulting in $169 \%$ increase in the incidence of ADR-related admissions (from 1.29\% in 2007 to $3.74 \%$ in 2011). On the other hand, incidence of ADR-related hospital admission identified from spontaneous report was $0.71 \%$. Similarly, incidence and the total number of ADR-related admissions identified from spontaneous reports were also increased. With respect to the number of deaths among patients with ADR-related admissions, average case fatality between 2007 and 2011 was about $11 \%$.

Table 3. Total number of ADR-related admissions from 2007 to 2011

\begin{tabular}{|c|c|c|c|c|c|c|c|}
\hline Year & 2007 & 2008 & 2009 & 2010 & 2011 & total & $\begin{array}{l}\% \text { change } \\
2007-2011\end{array}$ \\
\hline Total number of admissions & 52,955 & 55,764 & 55,309 & 57,041 & 62,001 & 283,070 & $0 \quad 17.08$ \\
\hline \multicolumn{8}{|l|}{ Administrative database } \\
\hline $\begin{array}{l}\text { Number of admissions with } \\
\text { "Drug-induced" codes }\end{array}$ & 479 & 507 & 882 & 1,003 & 909 & 3,780 & 89.77 \\
\hline $\begin{array}{l}\text { Number of admissions with } \\
\text { "external cause" codes }\end{array}$ & 202 & 378 & 1,018 & 1,138 & 1,240 & 3,976 & 513.86 \\
\hline Total number of ADRs-related admissions & 681 & 885 & 1,900 & 2,141 & 2,149 & 7,756 & 215.57 \\
\hline Incidence of ADRs-related admissions (\%) & 1.29 & 1.59 & 3.44 & 3.75 & 3.47 & 2.74 & 168.99 \\
\hline $\begin{array}{l}\text { Total number of deaths among patients } \\
\text { with ADRs-related admissions }\end{array}$ & 68 & 66 & 226 & 273 & 214 & 847 & 214.71 \\
\hline Case fatality $(\%)$ & 9.99 & 7.46 & 11.89 & 12.75 & 9.96 & 10.92 & -0.3 \\
\hline \multicolumn{8}{|l|}{ Spontaneous repot } \\
\hline Total number of ADRs-related admissions & 263 & 363 & 496 & 418 & 463 & 2,003 & 76.05 \\
\hline Incidence of ADR-related admissions (\%) & 0.5 & 0.65 & 0.90 & 0.73 & 0.75 & 0.71 & 50.00 \\
\hline
\end{tabular}

Table 4 describes the total number of ADRs with an "external cause" code during 2007 to 2011. As shown in the table, the most common classes of drug associated with ADRs were hormones and their synthetic substitutes and antagonists (Y42; 24\%), systematic antibiotic (Y40; 13.2\%), agents primarily affecting blood constitutes (Y44; 12.6\%), systematic agents (Y43;9.3\%), other and unspecified drugs (Y 57; 7.1\%), and analgesic, antipyretic and anti-inflammatory drugs (Y45; $6.5 \%)$, respectively. 
Table 4. Total number of admissions with an "external cause" code from 2007 to 2011

\begin{tabular}{|c|c|c|c|c|c|c|c|}
\hline ICD-1C & Description & $\begin{array}{l}2007 \\
(\%)\end{array}$ & $\begin{array}{c}2008 \\
(\%)\end{array}$ & $\begin{array}{c}2009 \\
(\%)\end{array}$ & $\begin{array}{r}2010 \\
(\%)\end{array}$ & $\begin{array}{c}2011 \\
(\%)\end{array}$ & $\begin{array}{c}\text { Total } \\
(\%)\end{array}$ \\
\hline Y42 & $\begin{array}{l}\text { Hormones and their synthetic } \\
\text { substitutes and antagonists }\end{array}$ & $12(5.94)$ & $11(2.91)$ & $226(22.20)$ & $324(28.47)$ & $381(30.72)$ & 954(23.99) \\
\hline $\mathrm{Y} 40$ & Systemic antibiotics & $32(15.84)$ & $61(16.14)$ & $156(15.32)$ & $147(12.92)$ & $130(10.48)$ & $526(13.23)$ \\
\hline Y44 & $\begin{array}{l}\text { Agents primarily affecting } \\
\text { blood Constituents }\end{array}$ & $51(25.25)$ & $100(26.46)$ & $112(11.00)$ & $112(9.84)$ & $126(10.16)$ & $501(12.60)$ \\
\hline Y43 & Primarily systemic agents & $8(3.96)$ & $11(2.91)$ & $82(8.05)$ & $125(10.98)$ & $142(11.45)$ & $368(9.26)$ \\
\hline Y57 & Other and unspecified drugs & $32(15.84)$ & $84(22.22)$ & $51(5.01)$ & $51(4.48)$ & $63(5.08)$ & $281(7.07)$ \\
\hline Y45 & $\begin{array}{l}\text { Analgesic, antipyretics and } \\
\text { anti-inflammatory drugs }\end{array}$ & $11(5.45)$ & $18(4.76)$ & $76(7.47)$ & $82(7.21)$ & $70(5.65)$ & $257(6.46)$ \\
\hline Y52 & $\begin{array}{l}\text { Agents primarily affecting the } \\
\text { cardiovascular system }\end{array}$ & $18(8.91)$ & $25(6.61)$ & $72(7.07)$ & $63(5.54)$ & $60(4.84)$ & $238(5.99)$ \\
\hline Y41 & $\begin{array}{l}\text { Other systemic anti-infectives } \\
\text { and antiparasitics }\end{array}$ & $8(3.96)$ & $11(2.91)$ & $57(5.59)$ & $66(5.80)$ & $75(6.05)$ & $217(5.46)$ \\
\hline Y54 & $\begin{array}{l}\text { Agents primarily affecting water-balance } \\
\text { and mineral and uric acid metabolism }\end{array}$ & $4(1.98)$ & $13(3.44)$ & $58(5.70)$ & $66(5.80)$ & $76(6.13)$ & $217(5.46)$ \\
\hline Y46 & Antiepileptic and anti-Parkinsonism drugs & $11(5.45)$ & $19(5.03)$ & $37(3.64)$ & $26(2.29)$ & $39(3.15)$ & $132(3.32)$ \\
\hline Y51 & $\begin{array}{l}\text { Drugs primarily affecting the autonomic } \\
\text { nervous system }\end{array}$ & $2(0.99)$ & $8(2.12)$ & $36(3.54)$ & $33(2.90)$ & $36(2.90)$ & $115(2.89)$ \\
\hline Y49 & $\begin{array}{l}\text { Psychotropic drugs, not elsewhere } \\
\text { Classified }\end{array}$ & $2(0.99)$ & $4(1.06)$ & $15(1.47)$ & $13(1.14)$ & $15(1.21)$ & $49(1.23)$ \\
\hline Y47 & $\begin{array}{l}\text { Sedatives, hypnotics and anti-anxiety } \\
\text { drugs }\end{array}$ & $7(3.47)$ & $4(1.06)$ & $14(1.38)$ & $8(0.70)$ & $12(0.97)$ & $45(1.13)$ \\
\hline Y59 & $\begin{array}{l}\text { Other and unspecified vaccines and } \\
\text { biological substance }\end{array}$ & $1(0.50)$ & $2(0.53)$ & $3(0.30)$ & $8(0.70)$ & $3(0.24)$ & $17(0.43)$ \\
\hline Y55 & $\begin{array}{l}\text { Agents primarily act smooth and skeletal } \\
\text { muscle and respiratory system }\end{array}$ & $1(0.50)$ & $1(0.27)$ & $6(0.59)$ & $3(0.26)$ & $4(0.32)$ & $15(0.38)$ \\
\hline Y53 & $\begin{array}{l}\text { Agents primarily affecting the } \\
\text { gastrointestinal system }\end{array}$ & $1(0.49)$ & $1(0.27)$ & $5(0.49)$ & $4(0.35)$ & $3(0.24)$ & $14(0.35)$ \\
\hline Y56 & $\begin{array}{l}\text { Topical agent primarily affecting skin } \\
\text { and mucous membranes }\end{array}$ & $1(0.50)$ & $2(0.53)$ & $5(0.49)$ & $3(0.26)$ & $1(0.08)$ & $12(0.30)$ \\
\hline Y58 & Bacterial vaccines & $0(0)$ & $2(0.53)$ & $4(0.39)$ & $4(0.35)$ & $2(0.16)$ & $12(0.30)$ \\
\hline $\mathrm{Y} 48$ & Anaesthetic and therapeutic gases & $0(0)$ & $0(0)$ & $2(0.19)$ & $0(0)$ & $2(0.16)$ & $4(0.10)$ \\
\hline Y50 & $\begin{array}{l}\text { Central nervous system stimulants, } \\
\text { not elsewhere classified }\end{array}$ & $0(0)$ & $1(0.27)$ & $1(0.09)$ & $0(0)$ & $0(0)$ & $2(0.05)$ \\
\hline & Total & 202 & 378 & 1,018 & 1,138 & 1,240 & 3,976 \\
\hline
\end{tabular}


As shown in Table 5, diagnoses most frequently associated with ADRs were drug induced neutropenia (46.35\%), drug induced hypoglycemia $(22.99 \%)$, generalized skin eruption $(11.06 \%)$, toxic liver disease with hepatic necrosis $(5.58 \%)$, and hypotension $(4.13 \%)$, respectively. When looking at the trend during the year 2007 to 2011, drug-induced hypoglycemia was the fastest growing ADRs.

In addition, we found that ADR-related admissions occurred slightly more frequent in female (54.6\%). Approximately $46 \%$ and $44 \%$ of ADRs occurred among patients aged between 17-59, and 60 years or older, respectively. Average length of stay of patients with ADRrelated admissions was estimated at 10.29 days.

Table 5. Total number of admissions with drug-induced codes from 2007-2011

\begin{tabular}{|c|c|c|c|c|c|c|c|}
\hline $\begin{array}{l}\text { ICD-10 } \\
\text { codes }\end{array}$ & Description & 2007 & 2008 & 2009 & 2010 & 2011 & Total \\
\hline D70 & Drug-induced neutropenia & $302(63.05)$ & $321(63.31)$ & $402(45.88)$ & $389(38.78)$ & $338(37.18)$ & $1752(46.35)$ \\
\hline E16.0 & $\begin{array}{l}\text { Drug-induced hypoglycaemia without } \\
\text { coma }\end{array}$ & $42(8.77)$ & $53(10.45)$ & 176(19.95) & $316(31.51)$ & $282(31.02)$ & $869(22.99)$ \\
\hline $\mathrm{L} 27.0$ & $\begin{array}{l}\text { Generalized skin eruption due to } \\
\text { drugs and medicaments }\end{array}$ & $71(14.82)$ & $42(8.28)$ & 112(12.70) & $98(9.77)$ & $95(10.45)$ & $418(11.06)$ \\
\hline K71.1 & Toxic liver disease with hepatic necrosis & $25(5.22)$ & $39(7.69)$ & $58(6.58)$ & $42(4.19)$ & $47(5.17)$ & $211(5.58)$ \\
\hline I95.2 & Hypotension due to drugs & $19(3.97)$ & $18(3.55)$ & $52(5.90)$ & $37(3.69)$ & $30(3.30)$ & $156(4.13)$ \\
\hline E15 & $\begin{array}{l}\text { Nondiabetic hypoglycaemic coma } \\
\text { Drug-induced insulin coma in nondiabetic }\end{array}$ & $3(0.63)$ & $3(0.59)$ & $21(2.38)$ & $63(6.28)$ & $62(6.82)$ & $152(4.02)$ \\
\hline $\mathrm{G} 25.3$ & Drug-induced myoclonus & $2(0.42)$ & $10(1.97)$ & $25(2.83)$ & $12(1.20)$ & $18(1.98)$ & $67(1.77)$ \\
\hline G95.8 & $\begin{array}{l}\text { Drug-induced other specified diseases of } \\
\text { spinal cord }\end{array}$ & $3(0.63)$ & $11(2.17)$ & $10(1.13)$ & $12(1.20)$ & $6(0.66)$ & $42(1.11)$ \\
\hline E27.3 & Drug-induced adrenocortical insufficiency & $3(0.63)$ & $2(0.39)$ & $7(0.79)$ & $5(0.50)$ & $1(0.11)$ & $18(0.48)$ \\
\hline D61.1 & Drug-induced aplastic anaemia & $1(0.21)$ & $2(0.39)$ & $2(0.23)$ & $2(0.20)$ & $8(0.88)$ & $15(0.40)$ \\
\hline L27.1 & $\begin{array}{l}\text { Localized skin eruption due to drugs and } \\
\text { medicaments }\end{array}$ & $1(0.21)$ & 0 & $5(0.57)$ & $5(0.50)$ & $4(0.44)$ & $15(0.40)$ \\
\hline G72.0 & Drug-induced myopathy & $2(0.42)$ & $2(0.39)$ & $3(0.34)$ & $2(0.2)$ & $4(0.44)$ & $13(0.34)$ \\
\hline L25.1 & $\begin{array}{l}\text { Unspecified contact dermatitis due to drugs } \\
\text { in contact with skin }\end{array}$ & 0 & $1(0.20)$ & 0 & $4(0.40)$ & $6(0.66)$ & $11(0.29)$ \\
\hline R50.2 & Drug-induced fever & 0 & 0 & 0 & $8(0.8)$ & $2(0.22)$ & $10(0.26)$ \\
\hline E03.2 & $\begin{array}{l}\text { Hypothyroidism due to medicaments and } \\
\text { other exogenous substances }\end{array}$ & 0 & 0 & $2(0.23)$ & $2(0.20)$ & $1(0.11)$ & $5(0.13)$ \\
\hline E24.2 & Drug-induced Cushing's syndrome & 0 & 0 & $3(0.34)$ & $1(0.10)$ & 0 & $4(0.11)$ \\
\hline $\mathrm{G} 24.0$ & Drug-induced dystonia & $1(0.21)$ & 0 & 0 & $1(0.10)$ & $1(0.11)$ & $3(0.08)$ \\
\hline I42.7 & $\begin{array}{l}\text { Cardiomyopathy due to drugs and other } \\
\text { external agents }\end{array}$ & 0 & 0 & 0 & $1(0.1)$ & $2(0.22)$ & $3(0.08)$ \\
\hline D59.0 & $\begin{array}{l}\text { Drug-induced autoimmune haemolytic } \\
\text { anaemia }\end{array}$ & 0 & 0 & $1(0.11)$ & $1(0.10)$ & 0 & $2(0.05)$ \\
\hline $\mathrm{G} 25.1$ & Drug-induced tremor & $1(0.21)$ & 0 & 0 & $1(0.10)$ & 0 & $2(0.05)$ \\
\hline G44.4 & $\begin{array}{l}\text { Drug-induced headache, not elsewhere } \\
\text { classified }\end{array}$ & $1(0.21)$ & $1(0.20)$ & 0 & 0 & 0 & $2(0.05)$ \\
\hline
\end{tabular}




\begin{tabular}{|c|c|c|c|c|c|c|c|}
\hline $\begin{array}{l}\text { ICD-10 } \\
\text { codes }\end{array}$ & Description & 2007 & 2008 & 2009 & 2010 & 2011 & Total \\
\hline G62.0 & Drug-induced polyneuropathy & 0 & 0 & $1(0.11)$ & 0 & $1(0.11)$ & $2(0.05)$ \\
\hline M32.0 & Drug-induced systemic lupus erythematosus & $2(0.42)$ & 0 & 0 & 0 & 0 & $2(0.05)$ \\
\hline M87.1 & Osteonecrosis due to drugs & 0 & 0 & 0 & $1(0.1)$ & $1(0.11)$ & $2(0.05)$ \\
\hline D64.2 & $\begin{array}{l}\text { Secondary sideroblastic anaemia due to } \\
\text { drugs and toxins }\end{array}$ & 0 & $1(0.2)$ & 0 & 0 & 0 & $1(0.03)$ \\
\hline K85.3 & $\begin{array}{l}\text { Secondary sideroblastic anaemia due to } \\
\text { drugs and toxins }\end{array}$ & 0 & $1(0.2)$ & 0 & 0 & 0 & $1(0.03)$ \\
\hline L23.3 & $\begin{array}{l}\text { Allergic contact dermatitis due to drugs in } \\
\text { contact with skin }\end{array}$ & 0 & $1(0.20)$ & 0 & 0 & 0 & $1(0.03)$ \\
\hline O68 & $\begin{array}{l}\text { Includes: fetal distress in labour or delivery } \\
\text { due to drug administration }\end{array}$ & 0 & 0 & $1(0.11)$ & 0 & 0 & $1(0.03)$ \\
\hline & Total & 479 & 507 & 882 & 1,003 & 909 & 3,780 \\
\hline
\end{tabular}

\section{DISCUSSIONS}

Incidence of ADR-related hospital admission, identified using administrative database was estimated at $2.74 \%$. Our findings are in line with that of the previous review in which the rate of ADRs ranged from $0.16 \%$ to $15.7 \%{ }^{6}$. Our findings are also in line with previous studies that use similar method to identify ADRs but slightly higher: Spain $1.69 \%^{12}$, England $0.5 \%$ to $0.9 \%{ }^{15,19}$, Portugal $1.26 \%{ }^{14}$. However, it should be noted that previous studies were conducted nationwide while our study was conducted in one tertiary care hospital so the rate might be higher due to the use of more complex medications compared to other types of hospitals. Nevertheless, when compared our results with those of the previous studies in Thailand $^{21-25}$, which found that incidence of ADRs among hospitalized patients varied widely ranging from $0.07 \%$ to $38.64 \%$, our detection rate was relatively low. It should be noted that method used in the previous studies were chart review while in this study administrative database was employed. Difference in method used to identify ADR may account for this difference. Nevertheless, we believed that the detection rate in our study may still under-estimated due to under-recognition and under-reporting of ADRs in routine hospital activity. However, when compared with the spontaneous report, our study confirmed that administrative database yields higher detection rate of ADRs than spontaneous report ${ }^{9}$. In this study, about $286 \%$ increase in incidence of ADR-related hospital admission was detected when using administrative database $(2.74 \%)$, as compared to spontaneous report $(0.71 \%)$.

When looking at trend of ADRs, similar to the previous studies ${ }^{14-16,19}$, we found that incidence of ADR-related hospital admission was increasing, which might be due to the introduction of new drugs, poly-pharmacotherapy, increasing aging population, and improvement of diagnostic and coding practice.

When looking at the major drugs groups most frequently associated with ADR, we found that hormones and their synthetic substitutes and antagonists e.g. insulin (Y42; 23.99\%), systemic antibiotics (Y40; 13.23\%), agents primarily affecting blood constituents e.g. anticoagulant (Y44; 12.60\%), systematic agents e.g. anti-neoplastic and immunosuppressant (Y43; 9.26\%), and analgesics, antipyretics and anti-inflammatory drugs (Y45; 6.46\%) were the most involved drug groups. Our findings are broadly similar to the previous studies ${ }^{12,15,19}$, which found that systematic agents particularly neoplastic drugs, analgesic drug, cardiovascular drug, antibiotics, anticoagulant were the most common drug classes associated with ADRs. The findings were also consistent to those previous studies in Thailand which found that 
antibiotic were the most involved drug classe ${ }^{20}$. However, it should be noted that the total number of drug prescribed was not available so direct comparison of the total number of ADRs associated with the class of drugs may not be appropriate. In addition, the important limitation of the external cause code in terms of the lack of specification of drugs or the broad grouping of drugs used (e.g. anticoagulants, antithrombotic drug, blood products and plasma substitutes were all grouped in code Y45) should be noted.

When considered the most common ADRs identified by drug-induced codes, our study found that drug-induced neutropenia, druginduced hypoglycemia, generalized skin eruption, toxic liver disease with hepatic necrosis, and hypotension were the most common ADRs identified from database. This is consistent with the major drugs groups most frequently associated with ADRs identified from external code as neutropenia was common side effect of antineoplastic drugs and systematic antibiotic while hypoglycemia was common side effect of insulin. In addition, our findings were similar to those of the previous study ${ }^{14}$, which found that neutropenia, hypoglycemia were the common ADRs found from hospital database. According to our results, caution should be made to monitor safety among patients who were prescribed with those drugs.

In contrast with previous studies ${ }^{4,6,15,19}$, which found that incidence of ADR-related hospitalization was quite high among elderly, our study found that incidence of ADRs among elderly was similar to those of the adult population. Nevertheless, it should be noted that direct comparison of the total number of ADR in each age group may not be appropriate as the total number of elderly patients and adult patients were not taken into account in the analysis. When looking at gender, consistent with the previous studies ${ }^{4,15}$, we found that ADRs occurred slightly more frequent in female than male. It has suggested that pharmacological, immunological and hormonal differences and the fact that women take more medications may explain this gender difference ${ }^{26}$.

It should be noted that our study was conducted in one tertiary care hospital in Thailand.
Generalization of the findings to other settings should be made with caution. Another limitation is inherent to the use of administration database, which often contain inaccurate coding and incomplete information on ADR as they are used primarily for administrative purposes, they may be less concerned with accurate recording of ICD. In addition, as the database was used for reimbursement purpose code creeping (distorting DRG codes towards those with higher reimbursement) may also occur. Finally, further evidence on economic burden of ADR related hospitalization is clearly need to bring attention of hospital administrators and health care policy makers to improve patient safety as well as to save this unnecessary cost.

Our study was the first study in less developed country examining incidence of ADR-related hospitalization at one tertiary care hospital using hospital routinely administration database. We confirmed that administrative database is useful and easily accessible method to determine proportion of the adverse events caused by drugs in less developed countries. At present, the Thai national database aggregating data from all patients admitted to each hospital in Thailand, who were Universal health Coverage and Civil Servant Medical Benefit Scheme beneficiary, which accounted for $80 \%$ of total population is available. As it is mainly used for reimbursement purpose it contains useful information related to ADR monitoring such as: age, gender, admission date, discharge date, hospital, ICD-10 $0^{\text {th }}$, Diagnosis Related Group (DRG). As the result, administrative database could be used to routinely monitor ADRs for national perspective as supplement to spontaneous reporting, which is currently used as a major surveillance mechanism to monitor ADRs in Thailand. As many less developed countries are moving towards Universal health care coverage, administrative database will be developed and made available for reimbursement purpose. Furthermore, future integration of computer systems within hospitals and the expansion of electronic prescribing and electronic health records in less developed countries will also make administrative database a more practical tool for pharmacovigilance at national level. 
In conclusion, we found that ADRrelated hospital admission was an increasing important public health problem accounted for $2.47 \%$ of total admissions. As detection and reporting ADR is crucial for improving and monitoring drug safety, we confirmed that administrative database is useful and feasible method to determine proportion of the adverse events caused by drugs in hospital in less developed countries. Nevertheless, improvement in the completeness, accuracy and standardization of coding should be promoted.

\section{ACKNOWLEGEMENTS}

This study was partially supported by Graduate School, Mahidol University. We thank all IT staff at Buddhachinaraj Phitsanulok Hospital, who provided technical support for the data collection.

\section{REFERENCES}

1. World Health Organization. International drug monitoring: the role of hospital. Switzerland, Geneva: World Health Organization, 1969.

2. Goettler M, Schneeweiss S, Hasford J. Adverse drug reaction monitoring--cost and benefit considerations. Part II: cost and preventability of adverse drug reactions leading to hospital admission. Pharmacoepidemiol Drug Saf. 1997;6(Suppl 3): S79-90.

3. Muehlberger N, Schneeweiss S, Hasford J. Adverse drug reaction monitoring--cost and benefit considerations. Part I: frequency of adverse drug reactions causing hospital admissions. Pharmacoepidemiol Drug Saf. 1997;6(Suppl 3):S71-7.

4. Pirmohamed M, James S, Meakin S, Green C, Scott AK, Walley TJ, et al. Adverse drug reactions as cause of admission to hospital: prospective analysis of 18820 patients. BMJ. 2004;329(7456):15-9.

5. Pirmohamed M, Breckenridge AM, Kitteringham NR, Park BK. Adverse drug reactions. BMJ. 1998;316(7140):1295-8.

6. Kongkaew C, Noyce PR, Ashcroft DM.
Hospital admissions associated with adverse drug reactions: a systematic review of prospective observational studies. Ann Pharmacother. 2008;42(7):1017-25.

7. Miguel A, Azevedo LF, Araújo M, Pereira AC. Frequency of adverse drug reactions in hospitalized patients: a systematic review and meta-analysis. Pharmacoepidemiol Drug Saf. 2012;21(11):1139-54.

8. Leendertse AJ, Visser D, Egberts AC, van den Bemt PM. The relationship between study characteristics and the prevalence of medication-related hospitalizations: a literature review and novel analysis. Drug Saf. 2010;33(3):233-44.

9. Miguel A, Azevedo LF, Lopes F, Freitas A, Pereira AC. Methodologies for the detection of adverse drug reactions: comparison of hospital databases, chart review and spontaneous reporting. Pharmacoepidemiol Drug Saf. 2013;22(1):98-102.

10. Vallano A, Cereza G, Pedròs C, Agustí A, Danés I, Aguilera C, et al. Obstacles and solutions for spontaneous reporting of adverse drug reactions in the hospital. $\mathrm{Br}$ J Clin Pharmacol. 2005;60(6):653-8.

11. Bandekar MS, Anwikar SR, Kshirsagar NA. Quality check of spontaneous adverse drug reaction reporting forms of different countries. Pharmacoepidemiol Drug Saf. 2010;19(11):1181-5.

12. Carrasco-Garrido P, de Andrés LA, Barrera VH, de Miguel GA, Jiménez-García R. Trends of adverse drug reactions relatedhospitalizations in Spain (2001-2006). BMC Health Serv Res. 2010;10:287.

13. Kane-Gill SL, Van Den Bos J, Handler SM. Adverse drug reactions in hospital and ambulatory care settings identified using a large administrative database. Ann Pharmacother. 2010;44(6):983-93.

14. Miguel A, Bernardo Marques, Freitas A, Lopes F, Azevedo L, Pereira AC. Detection of adverse drug reactions using hospital databases-a nationwide study in Portugal. Pharmacoepidemiol Drug Saf. 2013;22(8): 907-13.

15. Patel H, Bell D, Molokhia M, Srishanmuganathan J, Patel M, Car J, et al. Trends 
in hospital admissions for adverse drug reactions in England: analysis of national hospital episode statistics 1998-2005. BMC Clin Pharmacol. 2007;7:9.

16. Stausberg J, Hasford J. Drug-related admissions and hospital-acquired adverse drug events in Germany: a longitudinal analysis from 2003 to 2007 of ICD-10coded routine data. BMC Health Serv Res. 2011;11:134.

17. van der Hooft CS, Sturkenboom MC, van Grootheest K, Kingma HJ, Stricker BH. Adverse drug reaction-related hospitalisations: a nationwide study in The Netherlands. Drug Saf. 2006;29(2):161-8.

18. Waller P, Shaw M, Ho D, Shakir S, Ebrahim S. Hospital admissions for 'drug-induced' disorders in England: a study using the Hospital Episodes Statistics (HES) database. Br J Clin Pharmacol. 2005;59(2):213-9.

19. Wu TY, Jen MH, Bottle A, Molokhia M, Aylin P, Bell D, et al. Ten-year trends in hospital admissions for adverse drug reactions in England 1999-2009. J R Soc Med. 2010;103(6):239-50.

20. Akaleephan C, Kaewpanukrunsi W, Limwattananon C. Adverse drug reaction monitoring program. J Health Sci. 2004;
13(2):350-61.

21. Chiewchantanakit D. Study of adverse drug reactions at Queen Sirikit National Institute of Child Health. M.Sc. [Dissertation]. Bangkok: Mahidol University; 2000.

22. Panrong A. Incidence and cost impact of adverse drug reaction at Queen Sirikit National Institute of Child Health. M.Sc. [Dissertation]. Bangkok: Mahidol University; 1999.

23. Pomyen N. Characteristics of adverse drug reactions and patients at risk in medical wards, Ramatibodi hospital. M.Sc. [Dissertation]. Bangkok: Mahidol University; 2002.

24. Pongwecharak J. Intensive hospital monitoring of adverse drug reaction. M.Sc. [Dissertation]. Bangkok: Mahidol University; 1991.

25. Tragulpiankit $\mathrm{T}$. In-patent adverse drug reaction monitoring at the department of medicine, Ramathibodi hospital. M.Sc. [Dissertation]. Bangkok: Mahidol University; 1995.

26. Rodenburg EM, Stricker BH, Visser LE. Sex-related differences in hospital admissions attributed to adverse drug reactions in the Netherlands. Br J Clin Pharmacol. 2011; 71(1):95-104. 